\title{
Market Manipulation: A Comprehensive Study of Stock Pools
}

\author{
Guolin Jiang, Paul G. Mahoney and Jianping Mei* \\ Draft of September 2004
}

\begin{abstract}
Using a hand collected new data set, this paper examines in detail a classic account of stock market manipulation - the "stock pools" of the 1920s, which prompted the current anti-manipulation rules in the United States. We examine abnormal turnover and returns and the relationship between them, as well as the long-term performance of the selected stocks. We conclude that the evidence suggests informed trading rather than manipulation. Our findings have implications for regulatory policy as well as the investigation and prosecution of manipulation cases.
\end{abstract}

JEL classification: G24; G28; G38; K22

Keywords: Manipulation; Market regulation; Politics of finance

\footnotetext{
* Guolin Jiang is from Shanghai University of Finance and Economics, 777 Guoding Road, Shanghai, PR China, tel: 8621-65480991, jgl@jirtan.com; Paul G. Mahoney is from University of Virginia School of Law, 580 Massie Road, Charlottesville, VA 22903, tel: 434-924-3996, pmahoney@virginia.edu; Jianping Mei is from Stern School of Business, NYU, 44 West $4^{\text {th }}$ Street, New York, NY 10012, tel: 212-998-0354, jmei@stern.nyu.edu. We are grateful to Franklin Allen, Guojun Wu, and Chunsheng Zhou for helpful discussions.
} 


\section{Introduction}

Can an uninformed trader profit from buying and then selling an asset? Despite Friedman's (1953) conclusion that arbitrage would make such a strategy self-defeating, some financial economists have concluded that profitable "trade-based" manipulation is feasible. Allen and Gale (1992) and Aggarwal and Wu (2004) demonstrate the possibility of a pooling equilibrium in which the typical trader cannot distinguish informed investors and would-be manipulators, allowing the latter to influence prices strategically. Other models rely on investor irrationality or other departures from market efficiency. In Jarrow's (1992) model, prices have momentum, enabling a manipulator to establish a price trend and then profit by trading against it. Mei, Wu and Zhou (2004) demonstrate that a trader can exploit investor biases by buying to drive up prices, then selling at a profit.

The harder question is whether profitable trade-based manipulation is common in actual asset markets. Camerer (1998) describes an experimental attempt to manipulate prices (odds) in a horse race that failed to generate expected profits. The Securities and Exchange Commission (SEC) brings enforcement actions against alleged manipulators, primarily in small and illiquid stocks. During the internet boom in particular, the SEC took action against "pump and dump" schemes in which a trader made large purchases (sometimes coupled with the release of false information) and then sold after a price increase. ${ }^{1}$ Aggarwal and Wu (2004) study all stocks involved in SEC anti-manipulation enforcement actions from 1990 to 2001 and find that prices, trading volumes, and volatility rise during the alleged manipulation and prices fall afterwards, suggesting that profitable manipulation could have occurred.

Outside the limited context of penny stocks and other illiquid markets, the evidence of profitable trade-based manipulation is anecdotal. The most famous alleged manipulations are the stock pools of the 1920s, through which groups of investors

\footnotetext{
${ }^{1}$ An example is described in SEC Litigation Release 18137 (2003). A page on the SEC's web site (http://www.sec.gov/investor/online/pump.htm) is devoted to advising investors on how to spot and avoid internet "pump and dump" schemes. A separate page (http://www.sec.gov/divisions/enforce/internetenforce.htm) provides information about SEC enforcement actions involving internet fraud or manipulation.
} 
actively traded in a specified stock. The stock pools are the main cause of the current anti-manipulation laws in the United States and often motivate academic discussions of market manipulation. The apparent success of the stock pools continues to influence regulatory policies, such as SEC rules regarding stabilization during public offerings.

Mahoney (1999), however, studies the average price behavior of stocks traded by pools in 1928 and 1929 and argues that there is little evidence that pools were engaged in manipulation. While these stocks earned positive (but modest) abnormal returns on average around the time of pool formation, they did not subsequently earn abnormally negative average returns, as would be expected if the pool's trades artificially inflated stock prices. The qualitative evidence regarding pools is also ambiguous. Pool participants routinely testified that they were informed traders or were trading to add liquidity. The Senate's hearings were polemical and generated little hard evidence of manipulation.

In this paper, we undertake a more comprehensive examination of the pools using a much richer set of data, allowing us to study abnormal trading volume as well as returns, together with the relationship between them. In addition to averages, we look at the cross-sectional variation in return, turnover, and other measures among the pools. We also study the pool stocks' long-term abnormal returns. We discuss how recent findings from the theoretical and empirical literature on manipulation can be used in a forensic setting in which the qualitative evidence of manipulation is inconclusive, paying particular attention to the problem of distinguishing manipulation from informed trading. We find that the evidence is more consistent with the hypothesis that abnormal returns associated with the pools resulted from informed trading rather than successful tradebased manipulation. Finally, we note some implications of our study for the enforcement of anti-manipulation laws.

We begin with some basic characteristics of the pool stocks. Aggarwal and $\mathrm{Wu}$ (2004) find that stocks subject to manipulative trading tend to be small, illiquid, and volatile. In comparison, Maug (2002) shows that an informed trader can most easily profit from trades in highly liquid stocks, which provide more opportunities to camouflage the informed trades. We find that the pool stocks are comparable to their associated industry portfolios on measures of size and are more volatile and liquid, on 
average, than other companies in their industry. During the period of pool activity, the pool stocks experience both abnormally high trading volume and return, but both effects are small on average. Average volatility and liquidity both increase during a pool.

There are also important differences among the pool stocks. In particular, several were formed around the time of seasoned equity (rights) offerings in the subject stock. These stocks do not experience abnormally high trading volumes or returns during the pool.

We then investigate the relationship between trading volumes and returns. Tradebased manipulation, by definition, proceeds through large trades. The models in Jarrow (1992), Allen \& Gale (1992), Aggarwal \& Wu (2004) and Mei, Wu and Zhou (2004) involve would-be manipulators whose trades influence prices. Informal descriptions of manipulation, such as Leffler \& Farwell (1963), also focus on the manipulator's rapid accumulation of a large position in the target stock to create a mispricing. We find a strong cross-sectional relationship between abnormal turnover and return around the time of pool formation for the non-rights offering pool stocks.

We also look at the dynamic relationship between turnover and return using the framework developed by Llorente, Michaely, Saar \& Wang (2002). In their model, returns generated by informed trading tend to continue in the short run whereas returns generated by liquidity trading tend to reverse. We note, however, that return continuation in connection with potentially manipulative trading could also be evidence of price momentum generated by the manipulator. We find that the existence of a pool is, on average, associated with increased return continuation conditioned on turnover.

Finally, we investigate the long-term performance of the pool stocks. Even though the positive abnormal returns on the pool stocks are not reversed in the short run, we expect that if prices of pool stocks had been manipulated to artificially high levels, they would have experienced particularly hard landings during the 1929 stock market crash and the Depression. Indeed, the pool stocks underperform their industry averages during the decade beginning in late 1929. However, the underperformance is entirely accounted for by the stocks that were the subject of rights offerings at the time of the pool. The remaining stocks perform almost identically to their industry averages over the decade after the pool. Moreover, we find that the long-term performance is related to 
book-to-market and other valuation measures prior to the pool but not to the pool's activities.

In summary, while the pattern of stock price and trading volume could be consistent with market manipulation, there is no evidence that the stock pools' trades drove prices to artificially high levels. Therefore, we conclude that public investors were not harmed by pool operations. This finding is notable because Congress devoted substantial resources to uncovering evidence of manipulation on the New York Stock Exchange during the late 1920s. It appears, contrary to received wisdom, that this effort was unsuccessful. The size, liquidity, and disclosure standards in that market, although modest by current standards, may have been sufficient to protect investors against manipulation. This contrasts with the relatively small and illiquid markets that account for the majority of manipulation cases brought by the SEC (Aggarwal and Wu, 2004). It also contrasts with futures markets, in which the supply of the underlying deliverable commodity or financial instrument can be cornered, causing severe price distortions (Merrick, Naik and Yadav, 2003). Our results suggest, then, that enforcement resources can be focused on discrete segments of the securities markets.

We also note that it is difficult to reject a hypothesis of informed trading in favor of a hypothesis of trade-based manipulation solely by examining short-run trading data. As Llorente et al. (2002) demonstrate, informed trading, like manipulation, should result in high trading volume followed by abnormally high returns. Although manipulation, unlike informed trading, drives prices to an "artificial" level, the new price level must be sustained long enough to permit the manipulator to unwind his position. Our examination of pre-pool characteristics and post-pool long-term returns, therefore, is essential to determine whether the allegations of manipulation were warranted. The analytical tests developed in this paper could provide useful forensic tools in manipulation cases.

The rest of the paper is organized as follows. Section II describes the stock pools and Section III describes our data and compares the pool stocks and their associated industry portfolios just prior to pool formation. Section IV describes the average abnormal returns and turnover for the pools stocks during pool operations and analyzes cross-sectional differences among the pools. It also analyzes the dynamic relationship 
between turnover and return before and during the pools. Section V investigates the longrun returns on the pool stocks. Section VI concludes.

\section{The Stock Pools}

As described by Mahoney (1999), stock pools consisted of agreements, often written, among a group of traders to delegate authority to a single manager to trade in a specific stock for a specific period of time and then to share in the resulting profits or losses. After a lengthy investigation, the Senate Banking and Currency Committee (1932-34) concluded that pools represented attempts to manipulate the prices of the chosen stocks.

Other commentators provide colorful descriptions of the pools and their effects. Galbraith (1979, p. 79), for example, states that pools engaged in massive purchases in order to "increase prices and attract the interest of people watching the tape across the country... . If all went well, the public would come in to buy, and prices would rise on their own" enabling the pool to sell at a profit.

Galbraith's account suggests that rising volume caused a sustained price increase. Leffler and Farwell's (1963, p. 459) treatise on the stock market makes the same point explicitly:

A final device of the pool was artificial market activity. This consisted of a heavy "churning" of the stock in the market; it was bought and sold by the pool in heavy volume. ... Its purpose was obvious to all familiar with pool operations. The public must be attracted to the stock; few things attract speculators more quickly than a rising volume. The public's attitude became whetted in anticipation of "something big going on." It rushed in to buy before it was "too late." As the stock rose under increased activity, the public entered the market in ever increasing numbers; this was exactly the purpose of the operation.

Some contemporary authors, however, describe pool participants as informed traders rather than manipulators. Huebner (1934) and Pratt (1921) both argue that pool participants seek out undervalued stocks and purchase them quietly in order to profit from a later price rise. Their description contrasts markedly from that of Galbraith or Leffler and Farwell, who depict pools as trying to draw attention to their large purchases 
in order to generate interest in the stock. Allen and Gale's (1992) model distinguishes informed traders from uninformed large traders (manipulators). Manipulators trade in their model in order to convince others that they are informed, which leads other traders to purchase after observing the manipulator's purchases. Similarly, in Jarrow's (1992) model, small traders purchase after observing a sustained increase in the large trader's holdings.

Modern economists and lawyers have generally sided with Galbraith's account, in which pools are manipulative and therefore pernicious. Both Jarrow (1992) and Allen and Gale (1992) motivate their models with a discussion of famous examples of manipulation, including stock pools. In a discussion of recent accounting scandals, Malkiel (2002) analogizes attempts to boost prices through earnings management to 1920s-era market manipulation. Legal treatises such as Loss and Seligman (1989) depict pools as successful manipulations.

\section{Data and Characteristics of Pool Stocks}

\section{A. A Unique Data Set}

We use a new data set to examine the pre- and post-pool characteristics of the stocks that were subject to pools in the years 1928 and 1929. To the best of our knowledge, we have assembled the first daily return and trading volume data for all NYSE stocks from 1927 to 1929 . Our sources for daily prices and volumes are the Wall Street Journal and New York Times. The published prices are accompanied by a day-today price change that is adjusted to account for dividends and other distributions. Thus, discrepancies between the reported price change for day $t$, or $c_{t}$, and the actual difference in reported prices, $p_{t}-p_{t-1}$, occur on ex-distribution days, and the time series $c_{t}$ can accordingly be used to calculate daily total returns. As an added safeguard, we crosscheck those discrepancies against the distribution information contained in the Center for

Research in Security Prices (CRSP) monthly data set.

We also compute turnover and other measures of liquidity. Our data set includes, for each day, the number of shares outstanding taken from the monthly CRSP data base. We calculate daily turnover, or trading volume divided by the number of shares 
outstanding, as per Lo and Wang (2000). We also calculate, for the relevant period, the percentage of days on which the stock did not trade. No-trade days are not uncommon for U.S. equities during the 1920s. Bekaert, Harvey, and Lundblad (2003) use the proportion of trading days with no price change as a proxy for illiquidity. Unlike that paper, we have daily trading volumes as well as daily price changes and accordingly use no-trade days as a more direct proxy for liquidity than no-price-change days.

We also hand-collect the book value of common equity for each included stock, using accounting information from Moody's manuals. We define book value of common equity consistently with Fama and French (1993), although the diversity in accounting practices in the pre-SEC era complicates matters. One important issue is that some companies accounted for depreciation, depletion and amortization on the asset side of the balance sheet as per current practice, while others created a reserve on the liability side. We calculate the book value of equity as the sum of the common stock account, earned and capital surplus, and long-term reserves not including any depreciation, depletion, and/or amortization reserves. Because our goal is to model expected returns and not to test market efficiency, we update book values as of the balance sheet date, rather than with a lag as done in Fama and French $(1993,1995)$.

Our sample of pool stocks is the same as in Mahoney (1999). We begin with every stock named by the Senate as the subject of a pool in 1929 for which a starting date, $\tau$, can be determined from the investigators' records in the National Archives. The starting date for pool $i, \tau_{\mathrm{i}}$, is the date of the written agreement relating to stock $i$. We eliminate preferred stocks, mutual fund shares, and stocks that are not included in the CRSP data set in the month that includes the starting date. The sample consists of 55 of the 107 stocks identified in the Senate's report. Most of the missing stocks are those for which we are unable to locate a pool agreement in the National Archives. Table 1 lists the pool stocks and the corresponding pool formation dates.

One reason to suspect informed trading is the frequent appearance of insiders as pool participants. We cannot accurately measure how many pools included insiders because often the pool agreements we read redacted the signatories or only contained the first of multiple signature pages and did not otherwise list the participants. However, even with that limitation, by cross-checking the names of pool participants, when 
available, against the list of directors and officers contained in Moody's Manuals, we can determine that at least 12 of the 55 pools in our sample included a corporate officer or director.

Some of the pool agreements recite that the pool was formed to conduct a standby underwriting in connection with a rights offering or to engage in arbitrage between rights and the subject securities. At the time, seasoned equity offerings were commonly conducted as rights offerings. Returns on these stocks could be systematically different from the remainder of the sample even absent manipulation. Several studies find that companies conducting seasoned equity offerings are overpriced at the time of the offering (Loughran and Ritter 1995; Pontiff and Schill 2002). We accordingly construct subsamples consisting of pools formed within one month of a rights offering (based on the distribution information in the CRSP monthly file) and all others.

As a benchmark against which to compare realized returns and turnover on the pool stocks, we create industry-matched portfolios for each such stock. We include in the portfolio for pool stock $i$ every stock in the CRSP data set with the same 4-digit SIC code as $i$ as of $\tau_{\mathrm{i}}-1{ }^{2}$ We eliminate from the portfolios any stocks that were identified by the Senate's investigation as the subject of pools but that are not included in our sample of pool stocks.

\section{B. Pre-Pool Characteristics}

Aggarwal and $\mathrm{Wu}$ (2004) find that manipulators select stocks that are relatively small, illiquid, and volatile. Table 2 compares the pool and industry-matched portfolios just prior to pool formation. In the case of daily measures (return, turnover, and market capitalization), we calculate a time-series average (over the 60 trading days prior to pool formation) separately for each pool stock and each industry portfolio, then calculate descriptive statistics for the cross section of pools and portfolios. For volatility and liquidity measures, we make the appropriate time-series calculation separately for each stock in the control portfolios, calculate the portfolio average, and then average that

\footnotetext{
${ }^{2}$ For one of the pool stocks, there is no other stock with the same 4-digit SIC code. In that case, the control portfolio consists of all stocks with a 2-digit SIC match.
} 
measure over the 55 portfolios. We also provide separate information on the rights offering stocks and the others.

Unlike the manipulated stocks in Aggarwal and Wu's sample, the pool stocks are similar to the industry portfolios on size measures, although they have slightly higher market-to-book ratios. Interestingly, the pool stocks are substantially more liquid than the average stock in the matching portfolios. The pool stocks, on average, failed to trade on $6.2 \%$ of the trading days in the pre-pool period, compared to $18.7 \%$ for the stocks in the control portfolios. This is notable in light of Maug's (2002) conclusion that informed trading is more profitable for more liquid stocks and provides additional reason to suspect that at least some pools were engaged in informed trading. The pool stocks are more volatile on average than the stocks in the control portfolios, although most of the difference comes from the high pre-pool volatility of the rights offering stocks.

The pre-pool returns for the pool stocks are lower than that of the industry stocks, although again most of the difference is attributable to the rights offering stocks, which have a negative average return over the period. Average turnover is very similar between the pool stocks and associated portfolios.

\section{Returns and turnover during the pools}

The Senate's investigators did not gather comprehensive information about the pool operators' trades. We therefore attempt to infer when the pools were trading by looking at abnormal turnover as well as abnormal returns. We define an abnormal return for pool stock $i$ on date $t, A R_{i, t}$, as $A R_{i, t}=R_{i, t}-\frac{1}{K_{t}^{i}} \sum_{j=1}^{K^{i}} R_{j, t}$, where $\mathrm{K}_{\mathrm{t}}^{\mathrm{i}}$ is the number of stocks in the control portfolio corresponding to pool stock $i$ for which there is a return on date $t$. Cumulative abnormal returns are the sum of daily abnormal returns beginning on day -5 in event time. Following Barber and Lyon (1997), for purposes of testing whether the average cumulative abnormal return (ACAR) on the pool stocks is different from zero, we estimate the standard deviation of the ACAR for date $t$ as the cross-sectional sample standard deviation of cumulative abnormal returns for that date. We define abnormal turnover and assess statistical significance analogously. 


\section{A. Aggregate performance of pool stocks}

Figure 1 plots the average cumulative abnormal return and turnover for the pool stocks for the 60 trading days beginning with day -5 in event time. The abnormal return results are consistent with those reported by Mahoney (1999). The ACAR is positive throughout the period beginning at day -1 and reaches its peak very quickly. It is also modest in size, averaging approximately $4 \%$. It is easy to see that there is a positive relationship between ACAR and average cumulative abnormal turnover (ACAT) on days -5 through +2 . The plot is consistent with a period of purchasing by the pool starting immediately at the time of pool formation, with perhaps some informational leakage just prior to formation. This is, in turn, consistent with the "pumping" operation described in Mei, Wu and Zhou (2004), in which a manipulator purchases in large quantities, creating rising trading volume which is accompanied by rising prices. In the plot, the apparent period of accumulation is followed by an additional period of abnormally high turnover, perhaps as a consequence of the pools liquidating their long positions. We infer, therefore, that pools were net purchasers during approximately the period -5 to +2 in event time and net sellers during approximately the next 20 trading days.

Table 3 provides additional information about the average performance of the pool stocks during the entire period of assumed pool activity, or days -5 to +24 in event time. Average cumulative abnormal returns and turnover are significantly different from zero. Consistent with Aggarwal and Wu's (2004) sample of manipulated stocks, volatility and liquidity increase during the pool. However, the initial price rise does not reverse during the period when we assume the pools were selling.

The table also provides strong evidence that the rights offering pools are dissimilar to the remainder. Most important, their turnover during the pool is abnormally low rather than abnormally high. This is not surprising if these pools were largely engaged in standby underwritings. If the distribution of shares in the rights offering (which would take place over the counter and not generate additional reported volume) was going smoothly, there would be little reason for the underwriters to trade.

Finally, we look at extremes as well as averages. The pools that traded most heavily may be the most likely to have engaged in manipulation and may also have had the greatest impact on policy. The final column in Table 3 therefore analyzes the 10 
pools with the largest cumulative abnormal turnover during the assumed 30-day period of pool activity. Not surprisingly, these pools have a substantially larger average cumulative abnormal turnover than the remainder. They also have substantially higher abnormal returns. Interestingly, however, the pools did not significantly increase either volatility or liquidity for these stocks, which were on average more volatile and liquid than the remainder in the pre-pool period. These results reinforce the lesson that the pools operated principally in stocks that were volatile but also highly liquid.

\section{B. Cross-sectional analysis of pool returns and turnover}

As the discussion above makes clear, there is substantial cross-sectional variation in return and turnover among the pool stocks. Cumulative abnormal returns range from $24 \%$ to $+42 \%$, while cumulative abnormal turnover ranges from $-90 \%$ to $+115 \%$. The averages could be hiding pools whose performance is more consistent with manipulation.

An obvious initial question is whether abnormal turnover and abnormal return are correlated during the pool period. Figure 2 is a scatter-plot of cumulative abnormal return against cumulative abnormal turnover during the period from day -5 to +24 . There is a clear positive relationship between abnormal turnover and abnormal return. As shown in Table 4, the relationship is strengthened if we control for rights offerings. The second column in Table 4 estimates the following regression:

$$
C A R_{i}=\beta_{0}+\beta_{1} C A T_{i}+\beta_{2} R O_{i} * C A T_{i}
$$

where for each pool stock $i, \mathrm{CAR}_{\mathrm{i}}$ is the 30 -day cumulative abnormal return, $\mathrm{CAT}_{\mathrm{i}}$ is the cumulative average turnover, and $\mathrm{RO}_{\mathrm{i}}$ equals one if the pool stock was the subject of a rights offering within a month of pool formation and zero otherwise. For the rights offering stocks, there is a negative relationship between abnormal turnover and abnormal return. One possible explanation is that underwriters purchased for stabilization purposes if the stock price declined during the offering, but did not trade if the stock price remained steady or increased. Both results are strengthened if we restrict the analysis to the assumed "accumulation" period consisting of the 8 trading days beginning on day -5 . Again, the cross-sectional results are consistent with the "pumping" operation described 
in Mei, Wu and Zhou (2004) where a deep-pocketed manipulator pushes the stock price up by making large purchases. Holding everything else constant, the more stock the manipulator purchases, the higher the trading volume and price. The results do not, however, rule out the possibility of informed trading.

Another question is whether pool activity is associated with higher return volatility. We estimate a regression similar to equation (1) but with volatility (the standard deviation of daily returns during the pool period) as the dependent variable. We find no relationship, and the regression results are therefore not reported here.

What factors led pool operators to be more or less active? Again relying on the Aggarwal and $\mathrm{Wu}(2004)$ analysis, we would expect manipulation to be most probable in the case of smaller, more volatile, and less liquid stocks. As shown in Table 5, however, pool operators did not trade more heavily in smaller and less liquid stocks. Abnormal turnover during the pools is higher for stocks that were more volatile and had higher turnover prior to pool formation. This suggests the possibility that pool operators were attracted by more speculative stocks (which could produce higher volatility and turnover). ${ }^{3}$ As expected, there is considerably less trading in the stocks that were subject to rights offerings than in the other pools.

\section{The Dynamic Return-Turnover Relationship During Pools}

This section describes a simple model designed to shed additional light on the effects of the pools' trades. Llorente, Michaely, Saar and Wang (2002, hereafter LMSW) model the dynamic volume-return relationship for individual stocks under different trading motives. The model assumes that trades are motivated either by risk-sharing or information. Returns generated by uninformed traders' risk-sharing trades tend to reverse, whereas those generated by informed traders' private information trades tend to continue. The model cannot, however, distinguish between genuine informed trading and manipulation masquerading as informed trading.

We will briefly describe the LMSW model while referring the interested reader to the LMSW paper. The economy consists of two traded securities, a riskless bond and a

\footnotetext{
${ }^{3}$ See Mei, Scheinkman and Xiong (2003) for a discussion of volatility and trading volume for stocks whose prices have a speculative component.
} 
stock, and a non-traded asset. The bond is in unlimited supply at a constant and nonnegative interest rate. Each investor maximizes expected (exponential) utility conditional on his information set. Investors trade for two reasons. Uninformed investors trade to hedge risk by changing their holdings of the risky asset in response to changes in their holdings of the non-traded asset. Informed investors make hedging trades, but also trade to take advantage of their private information. After solving for the equilibrium price process, LMSW note that expected returns in period $t+1$ depend on the volume of trade in period $t$ and provide the following (approximate) dynamic return-volume relationship: ${ }^{4}$

$$
E\left[R_{t+1} \mid R_{t}, V_{t}\right]=C_{1} R_{t}+C_{2} V_{t} R_{t},
$$

where $R_{t}$ is return in time period $\mathrm{t}$ and $V_{t}$ is trading volume during period t. An important implication of the model is that returns generated by informed trades tend to continue, while returns generated by hedging trades tend to reverse. Note that in equation (2), $C_{l}$ provides the unconditional first-order return autocorrelation. The sign of $C_{2}$, then, indicates whether returns are positively or negatively autocorrelated, conditional on volume. Hedging trades should be followed by return reversal, leading to a negative $C_{2}$. Informed trades, by contrast, should be followed by return continuation, leading to a positive $C_{2}$.

We estimate a variant of the LMSW model that tests the association between abnormal turnover and the autocorrelation of abnormal returns. We use an additional interaction among prior-day abnormal turnover and return, and the presence of a pool. The intuition follows from the Jarrow (1992), Allen and Gale (1992), Aggarwal and Wu (2004) and Mei, Wu and Zhou (2004) models of successful manipulation, each of which implies short-term return continuance in the presence of a manipulator. Specifically, we estimate the following approximation of the LMSW model for stock $i$ over the period prior to and during pool operations:

\footnotetext{
${ }^{4}$ More precisely, the model relates returns to normalized volume and approximates the relationship using a Taylor series expansion of the resulting formula. For empirical purposes, however, LMSW simplify by relating returns to detrended log volume.
} 


$$
A R_{i, t+1}=\beta_{0}+\beta_{1} A R_{i, t}+\beta_{2} A R_{i, t} A V_{i, t}+\beta_{3} A R_{i, t} A V_{i, t} D_{i, t}^{p}+\varepsilon_{i, t+1} .
$$

where $\mathrm{AR}_{\mathrm{i}, \mathrm{t}}$ and $\mathrm{AV}_{\mathrm{i}, \mathrm{t}}$ are the abnormal return and turnover, respectively, for stock $i$ on date $t$, and $D_{i, t}^{p}$ is a dummy variable that equals 1 after pool formation and zero before pool formation.

The coefficient $\beta_{3}$ in equation 3 is of particular interest, as it captures the incremental abnormal return continuation (reversal), conditional on abnormal volume, during the pool period. Given a positive $\beta_{2}$, a positive $\beta_{3}$ would be consistent with either informed trading or manipulation due to pool trading. It could be a consequence of an increase in informed trading during the pool or evidence of a manipulator mimicking an informed trader. A negative $\beta_{3}$ would be evidence against either informed or manipulative trading and would suggest that pools traded for liquidity reasons.

We estimate the model for the period beginning on day -65 and continuing through the presumed "accumulation" period ending on day +2 . Those results are shown in Table 6 . The estimated coefficient $\beta_{2}$ is positive and significant, suggesting a generally high degree of informed trading for pool stocks. The estimated coefficient $\beta_{3}$ is also positive and significant, suggesting that the pools engaged either in genuine informed trading or manipulation masquerading as informed trading.

The magnitude of the $\beta_{3}$ coefficient falls as we re-estimate the model to encompass a longer time period after the commencement of the pool. For example, extending the sample period to day +10 produces a $\beta_{3}$ of $0.34(p<.01)$, compared to 0.45 as in Table 6. Extending the sample period all the way through the assumed end of pool operations, or day +24 , produces a $\beta_{3}$ of 0.11 , which is no longer significantly different from zero. This provides additional reason to believe that the pools' purchases were concentrated in a brief period around the time of signing the pool agreement. Table 6 also shows separate results for the rights offering stocks and the remainder. It is notable that only the latter group experiences increased return continuation conditional on volume during the existence of a pool.

While the results for individual stocks are generally insignificant and are not reported, there are few statistically significant estimated coefficients on the individual 
pool stocks. ${ }^{5}$ On average, the rights offering stocks have a negative estimated $\beta_{3}$ and, in one case, it is significant at the $1 \%$ level. Two pool stocks have an estimated $\beta_{3}$ that is positive and significant at the 5\% level. One of these, Radio Corp. of America, had substantial insider participation. The company was engaged in merger negotiations that were revealed shortly after the pool began, creating an obvious suspicion of insider trading (Mahoney 1999). The other pool traded in Standard Oil of California and consisted of a brokerage house and Herbert Fleishhacker, who controlled the AngloAmerican Bank (Standard Oil's transfer agent) and several energy companies in San Francisco, where Standard Oil was headquartered. ${ }^{6}$ Shortly after the formation of the pool on March 15, 1929, Standard Oil's price surged. Articles in the New York Times and Wall Street Journal on March 20 noted that the major oil companies had simultaneously and substantially raised gasoline prices in San Francisco and Los Angeles, signaling the end of a damaging price war. Once again, insider trading seems plausible.

\section{The long-term performance of the pool stocks}

The connection between trading volume and price changes during pools is consistent with models of successful manipulation and with informal descriptions of "pump and dump" schemes. However, the average magnitude of the abnormal returns is modest and there is no indication that these returns are reversed after the accumulation period ends. We therefore also consider the pool stocks' long-run performance. If, as in the traditional account, pools purchased to create price momentum and then sold overpriced stocks to gullible investors, these investors would eventually discover that the stocks were overvalued and the returns would be reversed.

Fortunately, there are some obvious eye-opening events after our period of interest - the October 1929 market crash and the Depression. The literature on the pools explicitly or implicitly concludes that the pool stocks, inflated by manipulative trading, realized greater losses than non-manipulated stocks during the market crash and

\footnotetext{
${ }^{5}$ We use a period ending on day +10 for these individual regressions in order to boost the power of the tests. These results are available upon request.

${ }^{6}$ Fleishhacker was also socially prominent in San Francisco. A Google search reveals that he is known as the "father of the San Francisco zoo."
} 
Depression. While Mahoney (1999) examined the possibility of short-term (six months) price reversal for pool stocks, he did not study their performance over a longer period.

We accordingly compare cumulative buy-and-hold monthly returns from September 1, 1929 through December 31, 1939, inclusive, on 54 pool stocks versus their industry-matched portfolios. One of the 55 pool stocks merged with one of its matched stocks shortly before the crash and is excluded from the sample.

Table 7 provides descriptive statistics for the long-run returns on the pool stocks and control portfolios. The pool stocks underperform their control portfolios during the decade that begins just before the crash. However, that underperformance is attributable entirely to the stocks that were the subject of rights offerings (which, as we have shown, did not experience unusually high trading volumes or returns during the pools). Returns on the remaining stocks very closely match their industries. Thus, even over a decade, the abnormal returns experienced during pool operations were not reversed.

We also look at the relative performance of the stocks traded by the most active pools, as defined in Table 3. These pool stocks underperform their industry portfolios, but by an insignificant amount. This again highlights the substantial cross-sectional variation in the pool stocks' long-run performance, and we accordingly test to see whether the differences are best explained by the pool's trading or by factors existing prior to the pool. Table 8 shows the results of regressions using long-term buy-and-hold abnormal returns (that is, the difference between the pool and control portfolio returns) as the dependent variable. The first column includes only pre-pool characteristics of the stocks, including market-to-book ratio, average daily abnormal returns, average daily abnormal turnover, and volatility during a 60 -day pre-pool period, and the standardized $\beta_{2}$ coefficient, which is a measure of informational asymmetry during the same pre-pool period. We also include an indicator for rights offerings.

The results show that measures suggesting overvaluation prior to the pool are related to long-run underperformance. Stocks that had a higher pre-pool market-to-book ratio or that experienced large abnormal returns prior to the pool have lower long-run abnormal returns. Consistent with modern evidence, stocks that are the subject of seasoned equity (rights) offerings have lower long-term performance. High 
informational asymmetry in the pre-pool period is also associated with inferior long-term performance.

The remaining columns add additional variables measuring the effects of the pool, including abnormal return, abnormal turnover, and volatility during the pool, as well as the standardized $\beta_{3}$ coefficient. None of the new variables enters significantly and their inclusion has almost no effect on the predictive power of the model.

The overall picture, then, is dramatically at odds with the traditional account of the pools. On average, the existence of a pool makes no difference in the long-term performance of the subject stock and only a modest (and positive) difference in the shortrun returns. Looking at the pool stocks individually, only one (Studebaker Automobile Corp.) is a strong candidate for a finding of trade-based manipulation based on a large increase in trading volume, a substantial abnormal short-run return, and an increase in return autocorrelation conditioned on volume during the pool, and long-run underperformance after the pool. The weakness in the case is that Studebaker's monthly returns are very similar to its industry's until 1933-35, when it experienced financial distress and then bankruptcy while the remainder of the automobile industry began to recover.

A plausible solution to the puzzle is that some of the pools were engaged in genuine informed trading. This would (as in the LMSW model) explain the increased volume and price in the short term as well as the unexceptional long-term performance of the pool stocks. It also meshes with the frequent presence of corporate insiders as pool participants. The rights offering pools, by contrast, do not present a puzzle - they seem to have been engaged in normal merchant banking services.

Even if the pool operators subjectively intended to drive prices from their fundamental levels, there is no evidence that they succeeded. This is notable because Congress devoted substantial time, money, and investigative expertise to finding instances of successful manipulation. This, by any reasonable interpretation of our data, it failed to do. Thus, either Congress's investigators did a poor job or manipulation was not a substantial problem on the New York Stock Exchange in the late 1920s.

Currently, legal proceedings against manipulators arise principally in two circumstances. One involves futures markets in a commodity or financial instrument that 
can be cornered around the time of delivery, as described by Merrick, Naik and Yadav (2003). The other involves stocks traded in relatively inefficient markets such as the "pink sheets" in the United States or the stock markets of emerging-market countries (Aggarwal \& Wu, 2004). It would be useful to understand how the risk of manipulation varies with the size and liquidity of the subject company.

From that perspective, we note that exchange-listed companies in the 1920s were dramatically different from today. The median market capitalization of a listed firm on the NYSE in 1929 was on the order of \$30 million and the median number of shares traded for a listed company on a typical day was in the hundreds. Yet the size and liquidity of these companies, coupled with the NYSE's own disclosure requirements, seem to have been sufficient to make successful manipulation rare. Of course, the amount of capital available to a would-be manipulator was smaller as well, so we cannot say that it would be impossible to manipulate stocks issued by similarly-sized companies today. Nevertheless, our results, coupled with those of other studies, suggest that successful trade-based manipulation is difficult for all but the smallest and most illiquid companies. Alternatively, the level of financial disclosure may be as or more important than size and liquidity per se. Mahoney (1997) describes the NYSE's pre-SEC disclosure and anti-manipulation rules. The exchange required financial disclosures and, as a means of preventing market corners, it also prohibited wash sales and other fraudulent trades that could be used to manipulate prices.

Our results also lend support to the SEC's 1997 decision to relax certain antimanipulation rules. For many years, the SEC's so-called 'trading rules" prohibited most share purchases by an issuer or underwriter during a public offering of the same class of shares. In 1997, however, the SEC ended many of these restrictions for stocks with a public float in excess of $\$ 150$ million and an average daily trading volume in excess of $\$ 1$ million. Those levels could perhaps be reduced without creating any significant risk of manipulation.

\section{Conclusion}

The stock pools are an important part of the historical justification for the federal securities laws' anti-manipulation provisions. They also provide part of the motivation 
for several prominent theoretical models of successful manipulation. There is, however, scant evidence on pool operations and their impact on stock liquidity, volatility, and pricing.

This paper assembles a new data set by hand-collecting daily price and trading volume data as well as book value from 1920s. By comparing pool stocks with industry matched portfolios, we find several important differences between pool operations and acknowledged instances of successful manipulation. Unlike the small and illiquid stocks studied by Aggarwal and Wu (2004), the average pool stock is of comparable size and more liquid than other companies in its industry. There are also important differences among the pool stocks. Stocks associated with rights offering pools do not experience abnormally high trading volume or price appreciation.

We also find some facts that are consistent with manipulation, but also with informed trading. Pool stocks display increased return continuation conditional on high trading volume. In the short run, abnormal returns are positively associated with trading volume for pool stocks, consistent with price manipulation in the Mei, Wu, and Zhou (2004) model. Nevertheless, we fail to find evidence that the pools caused abnormal performance during the market crash and Depression. The long-term performance of pool stocks is closely associated with valuation and turnover prior to pool formation but is not associated with measurable aspects of the pool operations.

As Mahoney (1999) notes, the New Deal-era Congress had substantial motivation and desire to uncover manipulation on the New York Stock Exchange from the late 1920s. Its investigators concluded that the pools presented the strongest case. In light of our findings, either manipulation was not a significant problem on the exchange or the investigators focused on the wrong phenomenon. One plausible conclusion is that the size, liquidity, and information disclosure of exchange-listed companies in the 1920s was sufficient to make manipulation difficult. This, in turn, suggests that regulatory resources may be safely focused on situations where those factors are not all present.

Our forensic analysis provides useful tools to researchers of market manipulation. Recent studies, such as Khwaja and Mian (2003) and Wu (2004), suggest that manipulation could still be quite prevalent in emerging markets. The tools developed in 
this paper could aid in the discovery and prosecution of these cases and help evaluate the effectiveness of regulatory systems in stamping out manipulation.

Our paper has left several issues unstudied. First, it might be interesting to analyze other aspects of liquidity such as the bid-ask spread during pool operations. A separate inquiry is whether the liquidity shock during pool operations was temporary or permanent. Aggarwal and Wu (2004) find that manipulated stocks experience improved long-term liquidity. Surprisingly, then, even successful trade-based manipulation may confer benefits that would have to be weighed against the resulting costs. These issues will require additional collection of historical data, which we will leave to an ongoing study. 


\section{References:}

Aggarwal, Rajesh and Guojun Wu, 2004. Stock Market Manipulation - Theory and Evidence, Working paper, Univ. of Michigan.

Allen, Franklin and Douglas Gale, 1992, Stock-Price Manipulation, The Review of Financial Studies, 5, 503-529.

Barber, Brad M. and J.D. Lyon, 1997. Detecting long-run abnormal stock returns: the empirical power and specification of test-statistics. Journal of Financial Economics 43, 341-372.

Bekaert, G., C. Harvey, and C. Lundblad, 2003. Liquidity and Expected Returns: Lessons from Emerging Markets, Working paper, Duke University.

Camerer, Colin F., 1998. Can Asset Markets be Manipulated? A Field Experiment with Racetrack Betting. Journal of Political Economy 106, 457-482.

Fama, Eugene F. and Kenneth R. French, 1993. Common risk factors in the returns on stocks and bonds. Journal of Financial Economics 33, 3-56.

Fama, Eugene F. and Kenneth R. French, 1995. Size and Book-to-Market Factors in Earnings and Returns. Journal of Finance 50, 131-155.

Friedman, Milton, 1953. Essays in Positive Economics. University of Chicago Press, Chicago, Illinois.

Galbraith, John Kenneth, 1979. The Great Crash. Houghton Mifflin, Boston, MA.

Huebner, S.S., 1934. The Stock Market. Second edition, Appleton-Century, New York.

Jarrow, Robert A., 1992. Market Manipulation, Bubbles Corners and Short Squeezes. Journal of Financial and Quantitative Analysis 27, 311-336.

Khwaja, Asim Ijaz and Atif Mian, 2003. Trading in Phantom Markets: An In-depth Exploration of an Emerging Stock Market. Working paper, Harvard University.

Leffler, G. L., and L. C. Farwell. 1963. The Stock Market, 3rd. ed. Ronald Press Co., New York.

Llorente, Guillermo, Roni Michaely, Gideon Saar and Jiang Wang, 2002. Dynamic Volume-Return Relation of Individual Stocks. Review of Financial Studies 15, 10051047. 
Lo, Andrew W. and Jiang Wang, 2000. Trading Volume: Definitions, Data Analysis, and Implications of Portfolio Theory, Review of Financial Studies 13, 257-300.

Loss, Louis and Joel Seligman, 1989. Securities Regulation. $3^{\text {rd }}$ ed. Little, Brown $\&$ Co., Boston, MA.

Loughran, Tim and Jay R. Ritter, 1995. The New Issues Puzzle. Journal of Finance 50, 23-51

Mahoney, Paul G., 1999. The Stock Pools and the Securities Exchange Act. Journal of Financial Economics 51, 343-369.

Mahoney, Paul G., 1997. The Exchange as Regulator. Virginia Law Review, 83: 14531500 .

Malkiel, Burton, 2002, The Market can Police Itself. Wall Street Journal, June 28, p. A10.

Maug, Ernst, 2002. Insider trading legislation and corporate governance. European Economic Review 46, 1569-1597.

Mei, Jianping, Jose Scheinkman and Wei Xiong, 2003. Speculative Trading and Stock Prices: An Analysis of Chinese A-B Share Premia. Princeton Univ. Working paper

Mei, Jianping., Guojun Wu and Chunsheng Zhou, 2004. Behavior Based Manipulation, NYU Working paper.

Merrick, John J., Narayan Y. Naik and Pradeep K. Yadav, 2003. Market Quality and Trader Behavior in a Manipulated Market: Anatomy of a Squeeze. Journal of Financial Economics, forthcoming.

Pontiff, Jeffrey and Michael J. Schill, 2002. Long-Run Seasoned Equity Offering Returns: Data Snooping, Model Misspecification, Or Mispricing? A Costly Arbitrage Approach. (working paper)

Pratt, Sereno S., 1921. The work of Wall Street: an account of the functions, methods and history of the New York money and stock markets. New York; D. Appleton \& Co.

United States Senate, Committee on Banking and Currency, 1932-34. Stock Exchange Practices: Hearings before the Committee on Banking and Currency, $72^{\text {nd }}$ Congress, $1^{\text {st }}$ Session. Government Printing Office; Washington, DC.

Wu, Guojun, 2004. A Detailed Analysis of a Stock Manipulation Case. University of Michigan, working paper. 
Table 1

Pool Stock Sample

\begin{tabular}{|c|c|}
\hline Company Name & Pool Formation Date \\
\hline Bush Terminal & $1 / 17 / 1928$ \\
\hline May Deptartment Stores & $1 / 17 / 1928$ \\
\hline St. Louis \& San Francisco R. R. Co. & $3 / 9 / 1928$ \\
\hline Simms Petroleum & $3 / 31 / 1928$ \\
\hline Curtis Aeroplane Co. & $4 / 3 / 1928$ \\
\hline Munsingwear & $4 / 26 / 1928$ \\
\hline South Porto Rico Sugar & $5 / 15 / 1928$ \\
\hline Cerro de Pasco & $5 / 21 / 1928$ \\
\hline Consolidated Cigar & $6 / 4 / 1928$ \\
\hline Pillsbury Flour Mills & $6 / 16 / 1928$ \\
\hline R.H. Macy \& Co. & $7 / 17 / 1928$ \\
\hline Childs \& Co. & $8 / 18 / 1928$ \\
\hline Continental Can Co. & $8 / 30 / 1928$ \\
\hline Kroger Grocery & $10 / 30 / 1928$ \\
\hline Underwood Elliott Fisher Co. & $10 / 30 / 1928$ \\
\hline American Sugar Refining Co. & $11 / 8 / 1928$ \\
\hline Weber \& Heilbroner & $11 / 15 / 1928$ \\
\hline National Dairy Co. & $11 / 19 / 1928$ \\
\hline Mid Continental Petroleum Co. & $11 / 21 / 1928$ \\
\hline Congress Cigar Co. & $12 / 3 / 1928$ \\
\hline R. J. Reynolds Tobacco Co. & $12 / 12 / 1928$ \\
\hline General Cigar Co. & $12 / 17 / 1928$ \\
\hline Lehn \& Fink Products & $12 / 21 / 1928$ \\
\hline Cluett Peabody Co. & $12 / 27 / 1928$ \\
\hline Marmon Motor Co. & $1 / 14 / 1929$ \\
\hline Studebaker & $1 / 14 / 1929$ \\
\hline Borden Co. & $1 / 18 / 1929$ \\
\hline Gotham Silk Hosiery & $1 / 30 / 1929$ \\
\hline Gimbel Brothers & $2 / 2 / 1929$ \\
\hline Miami Copper & 2/5/1929 \\
\hline General Cable & $2 / 15 / 1929$ \\
\hline Packard Motor Co. & $2 / 15 / 1929$ \\
\hline General Refractories & $2 / 27 / 1929$ \\
\hline Walworth Co. & $2 / 27 / 1929$ \\
\hline Radio Corporation of America & $3 / 7 / 1929$ \\
\hline Bethlehem Steel & $3 / 15 / 1929$ \\
\hline Standard Oil of California & $3 / 15 / 1929$ \\
\hline Purity Bakeries & $3 / 26 / 1929$ \\
\hline Oppenheim Collins Co. & $4 / 12 / 1929$ \\
\hline International Telephone \& Telegraph & $5 / 2 / 1929$ \\
\hline
\end{tabular}


A. G. Spalding \& Brothers

Murray Corporation of America

Pittsburgh \& West Virginia. R.R.

Spang Chalfante Co.

Gold Dust Corp.

American Ice

Telautograph

General American Tank Car Co.

Campbell Wyant Foundry Co.

American Commercial Alcohol

Archer Daniels Midland Corp.

L.A. Young Spring \& Wire Corp.

Missouri, Kansas \& Texas R.R.

Chrysler Co.

Columbia Carbon Co.
$5 / 8 / 1929$

$5 / 26 / 1929$

$5 / 27 / 1929$

$7 / 9 / 1929$

$7 / 10 / 1929$

$8 / 8 / 1929$

$8 / 12 / 1929$

$8 / 20 / 1929$

$8 / 21 / 1929$

$8 / 30 / 1929$

$8 / 30 / 1929$

$9 / 10 / 1929$

9/26/1929

$10 / 17 / 1929$

$10 / 30 / 1929$

The list of pool stocks is from Senate Stock Exchange Practices hearings (also known as the Pecora Hearings), Part 17, p. 7949. The formation dates are obtained from the records of the Pecora investigation contained in the National Archives. 
TABLE 2

Pool stocks and industry-matched control portfolios prior to pool formation

Means and standard deviations (in parentheses) are shown for return, turnover, size, volatility and liquidity measures for the 55 pool stocks and 55 industry-matched control portfolios over 60 trading days ending 6 days prior to the formation of the pools (days -65 through -6 in event time). Each pool stock is paired with a control portfolio consisting of all companies with the same 4-digit SIC code (in one case there is no 4-digit SIC match and the portfolio consists of all companies with the matching 2-digit SIC code). Daily return, turnover, market capitalization, book value, and market-to-book ratio are averaged over the event period for each stock and portfolio. The standard deviation of daily returns for each pool stock is calculated for the time series of returns during the sample period. The corresponding measure for a control portfolio is the average of the time-series standard deviations for the individual stocks in the portfolio. Trading days with no transactions is the number of days during the event period that a particular stock did not trade. The corresponding measure for a control portfolio is the average for the individual stocks in the portfolio.

\begin{tabular}{|c|c|c|c|c|c|c|}
\hline & $\begin{array}{l}\text { Pool } \\
\text { stocks }\end{array}$ & $\begin{array}{l}\text { Control } \\
\text { portfolios }\end{array}$ & $\begin{array}{c}\text { Pool stocks } \\
\text { excluding rights } \\
\text { offerings }\end{array}$ & $\begin{array}{c}\text { Control portfolios } \\
\text { excluding rights } \\
\text { offerings }\end{array}$ & $\begin{array}{l}\text { Pool stocks (rights } \\
\text { offerings only) }\end{array}$ & $\begin{array}{c}\text { Control portfolios } \\
\text { (rights offerings } \\
\text { only) }\end{array}$ \\
\hline $\mathrm{N}$ & \multicolumn{2}{|c|}{55} & \multicolumn{2}{|c|}{47} & \multicolumn{2}{|c|}{8} \\
\hline Daily return (\%) & $\begin{array}{c}0.081 \\
(0.330)\end{array}$ & $\begin{array}{c}0.151 \\
(0.202)\end{array}$ & $\begin{array}{c}0.112 \\
(0.248)\end{array}$ & $\begin{array}{c}0.151 \\
(0.206)\end{array}$ & $\begin{array}{l}-0.105 \\
(0.624)\end{array}$ & $\begin{array}{c}0.151 \\
(0.187)\end{array}$ \\
\hline Daily turnover (\%) & $\begin{array}{c}0.767 \\
(0.744)\end{array}$ & $\begin{array}{c}0.841 \\
(0.580)\end{array}$ & $\begin{array}{c}0.797 \\
(0.788)\end{array}$ & $\begin{array}{c}0.805 \\
(0.514)\end{array}$ & $\begin{array}{c}0.587 \\
(0.383)\end{array}$ & $\begin{array}{c}1.049 \\
(0.895)\end{array}$ \\
\hline $\begin{array}{l}\text { Market capitalization } \\
\text { (\$ millions) }\end{array}$ & $\begin{array}{c}94.3 \\
(156.6)\end{array}$ & $\begin{array}{c}92.7 \\
(184.1)\end{array}$ & $\begin{array}{c}85.6 \\
(150.7)\end{array}$ & $\begin{array}{c}99.0 \\
(197.8)\end{array}$ & $\begin{array}{c}145.7 \\
(190.9)\end{array}$ & $\begin{array}{c}56.0 \\
(49.8)\end{array}$ \\
\hline $\begin{array}{l}\text { Book value of equity } \\
\text { (\$ millions) }\end{array}$ & $\begin{array}{l}48.9 \\
(88.5)\end{array}$ & $\begin{array}{c}59.1 \\
(137.5)\end{array}$ & $\begin{array}{c}49.8 \\
(92.8)\end{array}$ & $\begin{array}{c}65.1 \\
(148.0)\end{array}$ & $\begin{array}{c}43.4 \\
(61.6)\end{array}$ & $\begin{array}{l}23.5 \\
(16.6)\end{array}$ \\
\hline Market-to-book ratio & $\begin{array}{l}2.43 \\
(2.39)\end{array}$ & $\begin{array}{c}2.19 \\
(1.35)\end{array}$ & $\begin{array}{c}2.12 \\
(2.35)\end{array}$ & $\begin{array}{c}2.15 \\
(1.41)\end{array}$ & $\begin{array}{l}4.20^{*} \\
(1.91)\end{array}$ & $\begin{array}{c}2.42 \\
(0.886)\end{array}$ \\
\hline $\begin{array}{l}\text { Standard deviation of } \\
\text { daily return }(\%)\end{array}$ & $\begin{array}{l}2.20 * * \\
(0.891)\end{array}$ & $\begin{array}{c}1.85 \\
(0.903)\end{array}$ & $\begin{array}{l}2.08^{*} \\
(0.723)\end{array}$ & $\begin{array}{l}1.80 \\
(0.837)\end{array}$ & $\begin{array}{c}2.95 \\
(1.39)\end{array}$ & $\begin{array}{c}2.21 \\
(1.23)\end{array}$ \\
\hline $\begin{array}{l}\text { Trading days with no } \\
\text { transactions }(\%)\end{array}$ & $\begin{array}{c}6.18 * * * \\
(14.6)\end{array}$ & $\begin{array}{c}18.7 \\
(16.6)\end{array}$ & $\begin{array}{c}5.10 * * * \\
(9.93)\end{array}$ & $\begin{array}{c}17.9 \\
(14.5)\end{array}$ & $\begin{array}{c}12.5 \\
(30.7)\end{array}$ & $\begin{array}{c}23.3 \\
(26.6)\end{array}$ \\
\hline
\end{tabular}

$*, * *, * * *$ pool stock and control portfolio means are different at the $10 \%, 5 \%$ and $1 \%$ levels, respectively. 


\section{TABLE 3}

\section{Characteristics of pool stocks during pool operations}

All measures are for the period from day -5 to +24 in event time, except as otherwise noted. The measure of volatility is the standard deviation of daily nominal returns. The measure of liquidity is the percentage of days with no trading; a positive number indicates fewer such days. The change in volatility and liquidity is calculated with respect to a pre-pool period consisting of days -64 to -6 . Standard errors are calculated as the cross-sectional standard deviation divided by the square root of the sample size.

\begin{tabular}{lllll}
\hline Measure & $\begin{array}{l}\text { All } \\
\text { pools }\end{array}$ & $\begin{array}{l}\text { Excluding } \\
\text { rights offerings }\end{array}$ & $\begin{array}{l}\text { Rights } \\
\text { offerings only }\end{array}$ & $\begin{array}{l}\text { Most } \\
\text { active }\end{array}$ \\
\hline $\mathrm{n}$ & 55 & 47 & 8 & 10 \\
Average cumulative abnormal return, & $4.14^{* * *}$ & $4.79^{* * *}$ & 0.31 & $9.56^{* * *}$ \\
days -5 to +2 & $(0.96)$ & $(0.95)$ & $(3.38)$ & $(1.87)$ \\
Average cumulative abnormal turnover, & $5.40^{* * *}$ & $7.36^{* * *}$ & -6.08 & $19.92^{* * *}$ \\
days -5 to +2 & $(1.44)$ & $(1.40)$ & $(3.57)$ & $(2.39)$ \\
Average cumulative abnormal return & $3.79^{* *}$ & $3.70^{* *}$ & 4.34 & $11.06^{* *}$ \\
& $(1.62)$ & $(1.81)$ & $(3.56)$ & $(3.89)$ \\
Average cumulative abnormal turnover & $11.65^{* *}$ & $17.64^{* * *}$ & $-23.55^{*}$ & $72.46^{* * *}$ \\
& $(4.96)$ & $(4.97)$ & $(12.01)$ & $(8.63)$ \\
Change in volatility from pre-pool period & $0.61^{* *}$ & $0.49^{* * *}$ & 1.27 & 0.51 \\
& $(0.25)$ & $(0.18)$ & $(1.40)$ & $(0.28)$ \\
Change in liquidity (decrease in no-trade & $2.12^{*}$ & $1.77^{*}$ & 4.17 & 0.17 \\
days) from pre-pool period & $(1.20)$ & $(0.91)$ & $(6.58)$ & $(0.52)$ \\
\hline
\end{tabular}

$*, * *, * * *$ : significantly different from zero at the $10 \%, 5 \%$ and $1 \%$ levels, respectively 


\section{TABLE 4}

Regressions: Pool Abnormal Turnover and Abnormal Return

The dependent variable in both regressions is cumulative abnormal return on each of the 55 pool stocks during the period of pool operations, which we assume to be days -5 to +24 in event time. The variable "Rights" is an indicator that equals one for stocks that were the subject of rights offerings within one month of pool formation and zero for all other stocks.

\begin{tabular}{lcc}
\hline Variable & Model 1 & Model 2 \\
\hline (Constant) & 2.41 & 1.17 \\
& $(1.60)$ & $(1.71)$ \\
Cumulative abnormal turnover & $0.12^{* * *}$ & $0.16^{* * *}$ \\
& $(0.04)$ & $(0.05)$ \\
Rights * Cumulative abnormal turnover & & $-0.21^{*}$ \\
Adjusted R-square & & $(0.12)$ \\
\hline
\end{tabular}

$*, * *, * * *$ significantly different from zero at the $10 \%, 5 \%$ and $1 \%$ levels, respectively 


\section{TABLE 5}

Regression: Abnormal Turnover and Pre-pool Characteristics

The dependent variable is cumulative abnormal turnover for each of the 55 pool stocks during the period of pool operations, which we assume to be days -5 to +24 in event time. Market capitalization and market-to-book ratio are measured for each pool stock on day 6. Pre-pool volatility and abnormal turnover are measured over the period from day -65 to -6 .

\begin{tabular}{lcc}
\hline Variable & Model 1 & Model 2 \\
\hline Constant) & -12.9 & $-21.7^{*}$ \\
& $(13.2)$ & $(11.9)$ \\
Market capitalization & 0.005 & 0.009 \\
& $(0.033)$ & $(0.029)$ \\
Market-to-book ratio & -1.01 & 0.812 \\
& $(2.19)$ & $(2.00)$ \\
Volatility prior to pool & 6.46 & $12.7^{* *}$ \\
& $(6.32)$ & $(5.85)$ \\
Abnormal turnover prior to pool & $18.7^{* *}$ & $14.9 * *$ \\
& $(7.08)$ & $(6.37)$ \\
No-trade days prior to pool & -31.6 & -28.5 \\
& $(39.3)$ & $(34.9)$ \\
Rights offering & & $-49.5^{* * *}$ \\
& & $(13.2)$ \\
Adj. $\mathrm{R}^{2}=0.29$ & .134 & .317 \\
\hline
\end{tabular}

$*, * *, * * *$ significantly different from zero at the $10 \%, 5 \%$ and $1 \%$ levels, respectively 
TABLE 6

Regressions: Abnormal Return Continuation and Abnormal Turnover

This table presents an estimation of the LMSW model for stock $i$ over the period from days -65 to +2 :

$$
A R_{i, t+1}=\beta_{0}+\beta_{1} A R_{i, t}+\beta_{2} A R_{i, t} A V_{i, t}+\beta_{3} A R_{i, t} A V_{i, t} D_{i, t}^{p}+\varepsilon_{i, t+1} .
$$

where $\mathrm{AR}_{\mathrm{i}, \mathrm{t}}$ and $\mathrm{AV}_{\mathrm{i}, \mathrm{t}}$ are the abnormal return and turnover, respectively, for stock $i$ on date $t$, and $D_{i, t}^{p}$ is a dummy variable that equals 1 after pool formation and zero before pool formation. The equation is jointly estimated for all pool stocks.

\begin{tabular}{lccccc}
\hline & $\beta_{0}$ & $\beta_{1}$ & $\beta_{2}$ & $\beta_{3}$ & Adj. $\mathrm{R}^{2}$ \\
\hline Entire sample & 0.010 & $-0.093 * * *$ & $0.013 *$ & $0.045^{* * *}$ & 0.013 \\
& $(0.049)$ & $(0.018)$ & $(0.007)$ & $(0.013)$ & \\
\hline Rights offering stocks & -0.017 & -0.074 & $0.074 *$ & 0.019 & 0.025 \\
only & $(0.177)$ & $(0.046)$ & $(0.042)$ & $(0.054)$ & \\
\hline Excluding rights & 0.021 & $-0.091 * * *$ & 0.009 & $0.037 * * *$ & 0.009 \\
offering stocks & $(0.050)$ & $(0.019)$ & $(0.007)$ & $(0.014)$ & \\
\hline
\end{tabular}

$*, * *, * * *$ significantly different from zero at the $10 \%, 5 \%$ and $1 \%$ levels, respectively 


\section{TABLE 7}

Long-run returns on pool and industry-matched stocks

The table shows descriptive statistics for cumulative buy-and-hold monthly returns (in \%) on 54 pool stocks and 54 industry-matched portfolios during the period September 1, 1929 through December 31, 1939.

\begin{tabular}{lcccc}
\hline & Mean & Maximum & Minimum & $\begin{array}{c}\text { Standard } \\
\text { deviation }\end{array}$ \\
\hline $\begin{array}{l}\text { Pool Stocks } \\
\text { Control portfolios }\end{array}$ & -40.79 & 399.86 & -100 & 80.59 \\
& -23.74 & 524.15 & -91.98 & 88.37 \\
$\begin{array}{l}\text { Pool stocks excluding rights } \\
\text { offerings }\end{array}$ & -38.38 & 399.86 & -100 & 84.45 \\
$\begin{array}{l}\text { Control portfolios excl. rights } \\
\text { offerings }\end{array}$ & -38.34 & 71.7 & -91.98 & 37.8 \\
$\begin{array}{l}\text { Pool stocks (rights offerings only) } \\
\text { Control Portfolios (rights offerings } \\
\text { only) }\end{array}$ & -56.96 & 32.22 & -99.25 & 48.49 \\
& 74.29 & 524.15 & -66.12 & 212.49 \\
$\begin{array}{l}\text { 10 most active pools } \\
\text { Control portfolios }\end{array}$ & -62.92 & 63.82 & -100 & 51.78 \\
\hline
\end{tabular}




\section{TABLE 8}

Regressions: Long-term abnormal returns versus pre-pool and pool characteristics

The dependent variable is the cumulative buy-and-hold abnormal return on each pool stock for the period September 1929 through December 1939. Abnormal returns are calculated as the monthly difference between the return on the pool stock and its associated industry portfolio. The estimated $\beta_{2}$ and $\beta_{3}$ coefficients are taken from the regressions reported in Table 6 . Pre-pool abnormal return, abnormal turnover, and volatility are calculated from days -64 to -6 , and the same variables during the pool are calculated from days -5 to +24 .

\begin{tabular}{|c|c|c|c|c|c|c|}
\hline Variable & Model 1 & Model 2 & Model 3 & Model 4 & Model 5 & Model 6 \\
\hline \multirow[t]{2}{*}{ (Constant) } & -54.24 & -54.84 & -51.77 & -55.31 & -50.45 & -51.91 \\
\hline & $(40.59)$ & $(41.21)$ & $(40.63)$ & (40.99) & $(40.47)$ & $(41.68)$ \\
\hline \multirow{2}{*}{$\begin{array}{l}\text { Pre-pool market-to- } \\
\text { book }\end{array}$} & $-13.34 * *$ & $-13.33 * *$ & $-15.40 * *$ & $-13.43 * *$ & $-13.07 * *$ & $-15.14 * *$ \\
\hline & $(6.13)$ & $(6.20)$ & $(6.44)$ & $(6.18)$ & $(6.10)$ & (6.69) \\
\hline \multirow{2}{*}{$\begin{array}{l}\text { Pre-pool cumulative } \\
\text { abnormal return }\end{array}$} & $-149.12 * * *$ & $-147.71 * * *$ & $-156.52 * * *$ & $-151.71 * * *$ & $-145.83 * * *$ & $-149.46^{* * *}$ \\
\hline & $(43.41)$ & $(44.85)$ & $(43.96)$ & $(44.11)$ & $(43.24)$ & $(45.60)$ \\
\hline \multirow{2}{*}{$\begin{array}{l}\text { Pre-pool cumulative } \\
\text { abnormal turnover }\end{array}$} & 7.61 & 7.42 & -4.40 & 8.56 & -0.49 & -10.93 \\
\hline & $(18.96)$ & $(19.20)$ & $(22.21)$ & $(19.23)$ & (19.94) & $(24.52)$ \\
\hline \multirow[t]{2}{*}{ Pre-pool volatility } & $38.22 *$ & $38.81^{*}$ & $34.07 *$ & 33.94 & $39.06 *$ & 34.77 \\
\hline & (19.73) & $(20.32)$ & $(20.12)$ & $(21.84)$ & $(19.63)$ & $(22.32)$ \\
\hline \multirow[t]{2}{*}{ Standardized $\beta_{2}$} & $-92.74 * * *$ & $-92.14 * *$ & $-90.33 * *$ & $-89.83 * *$ & $-171.28 * *$ & $-148.20 *$ \\
\hline & $(34.30)$ & $(34.89)$ & $(34.35)$ & $(35.13)$ & $(71.60)$ & $(77.19)$ \\
\hline \multirow[t]{2}{*}{ Rights offering } & $-129.84 * * *$ & $-130.39 * * *$ & $-111.23 * *$ & $-131.99 * * *$ & $-139.72 * * *$ & $-122.77 * *$ \\
\hline & $(42.51)$ & $(43.116)$ & $(46.12)$ & $(43.11)$ & $(43.00)$ & $(50.23)$ \\
\hline \multicolumn{2}{|l|}{ Cumulative abnormal } & -.164 & & & & -0.703 \\
\hline \multicolumn{2}{|l|}{ return during pool } & $(1.11)$ & & & & $(1.277)$ \\
\hline \multirow{2}{*}{\multicolumn{2}{|c|}{$\begin{array}{l}\text { Cumulative abnormal } \\
\text { turnover during pool }\end{array}$}} & & 0.56 & & & 0.553 \\
\hline & & & $(0.54)$ & & & $(0.662)$ \\
\hline \multirow[t]{2}{*}{ Volatility during pool } & & & & 3.82 & & 2.211 \\
\hline & & & & $(8.07)$ & & $(8.368)$ \\
\hline \multirow[t]{2}{*}{ Standardized $\beta_{3}$} & & & & & -92.47 & -73.02 \\
\hline & & & & & $(74.13)$ & $(79.14)$ \\
\hline Adjusted R-square & .313 & .298 & .314 & .301 & .321 & .289 \\
\hline
\end{tabular}

$*, * *, * * *$ significantly different from zero at the $10 \%, 5 \%$ and $1 \%$ levels, respectively 


\section{FIGURE 1}

Cumulative average abnormal return and turnover on pool stocks

Abnormal return (turnover) is the difference between the return (turnover) on the pool stock and the industry-matched portfolio.

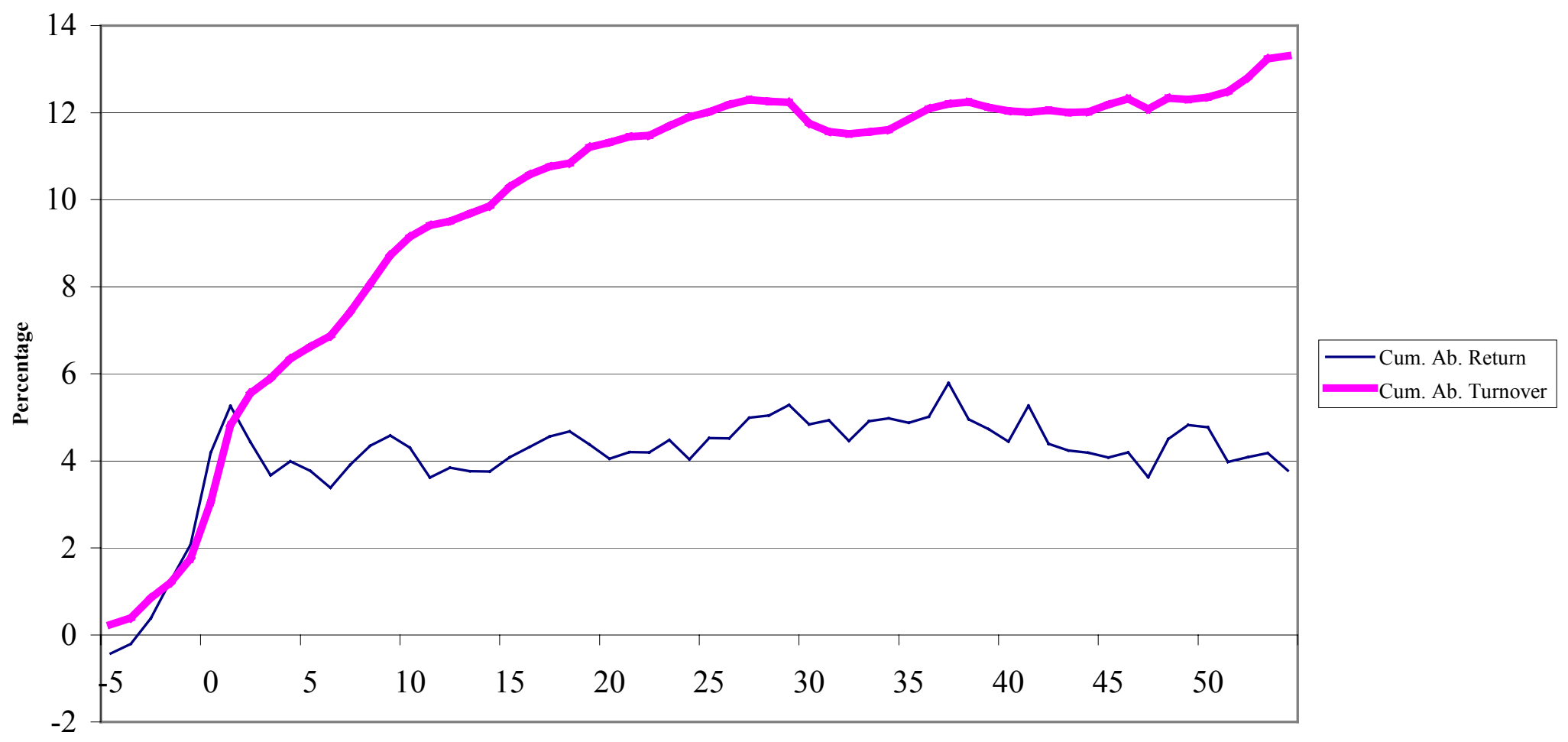

Pool Formation Date 


\section{FIGURE 2}

Cumulative abnormal return versus cumulative abnormal turnover for pool stocks

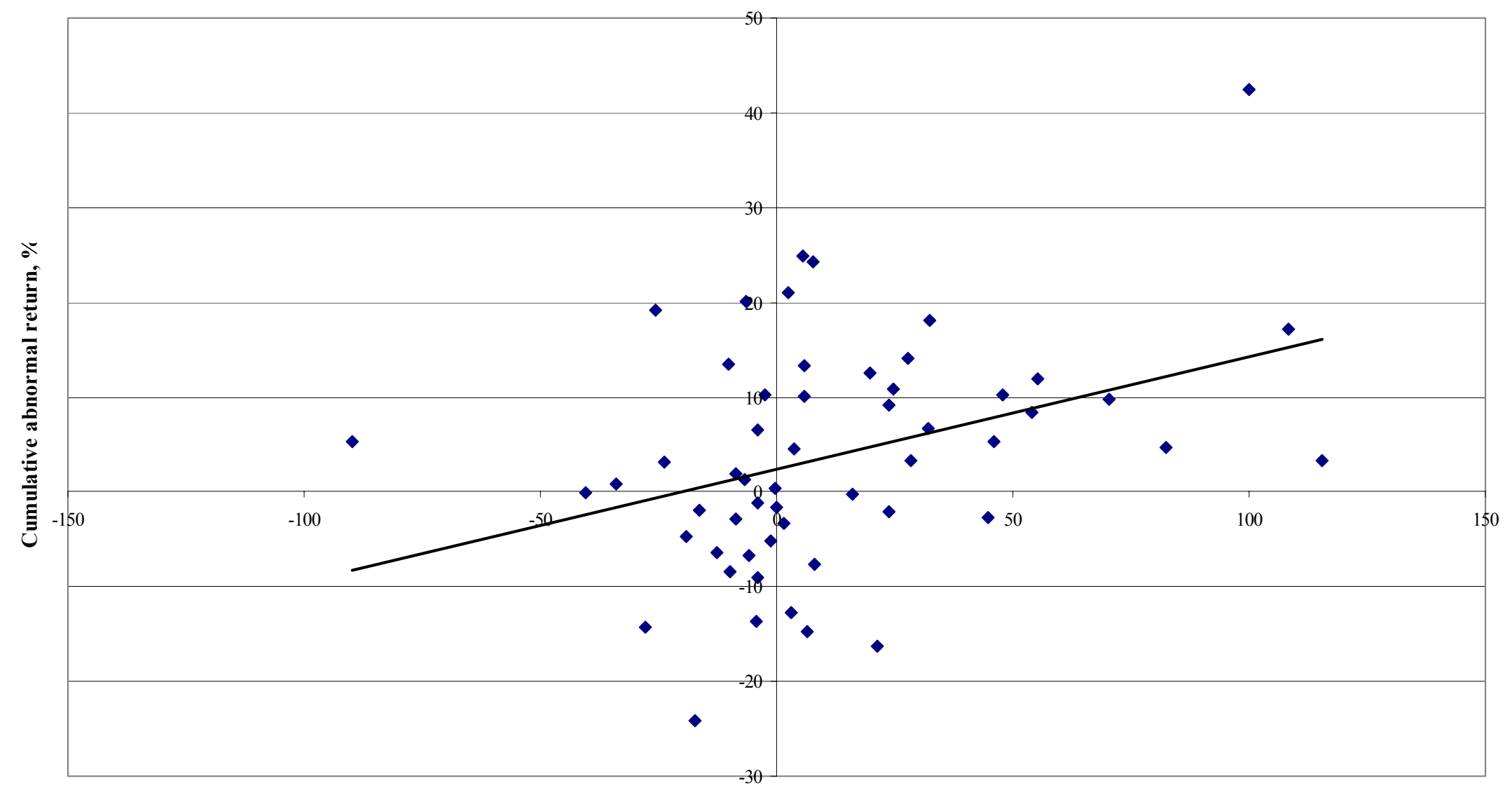

Cumulative abnormal turnover, \%

Cumulative abnormal returns and turnover are measured for each of the 55 pool stocks beginning on day -5 and ending on day +24 in event time, with day 0 the day on which the pool agreement began. 